\title{
Energy consumption, economic growth and pollution in Saudi Arabia
}

\section{Haider Mahmood $^{\mathrm{a}}$, Tarek Tawfik Yousef Alkhateeb ${ }^{\mathrm{a}, \mathrm{b}}$, Maleeha Mohammed Zaaf Al-Qahtani ${ }^{\mathrm{c}}$, Zafrul Allama, Nawaz Ahmad ${ }^{d}$ and Maham Furqan ${ }^{\mathrm{e}}$}

${ }^{a}$ College of Business Administration, Prince Sattam bin Abdulaziz University, Al-Kharj, Saudi Arabia

${ }^{b}$ Kafr Elshiekh University, Kafr Elshiekh 33511, Egypt

${ }^{c}$ College of Education, Prince Sattam bin Abdulaziz University, Al-Dilam 16213, Saudi Arabia

${ }^{d}$ University of Lahore, Lahore 54590, Pakistan

${ }^{e} S \& P$ Global Market Intelligence, Islamabad 44000, Pakistan

\section{H R O N I C L E}

Article history:

Received: September 15, 2019

Received in revised format: No-

vember 92019

Accepted: November 9, 2019

Available online:

November 9, 2019

Keywords:

$\mathrm{CO}_{2}$ emissions

Energy consumption

Economic Growth

\section{A B S T R A C T}

Economic growth is very basic need of any economy but its environmental effects should not be ignored. We investigate the environmental effects of economic growth and energy consumption of Saudi Arabia. The study uses data of a period 1968-2014 and cointegration test and corroborates a long- and short-run relationships. The results indicate that economic growth and energy consumption contributes in $\mathrm{CO}_{2}$ emissions in both long- and short-run. It means that increasing economic growth of the Kingdom has social cost on the economy in terms of pollution emissions. Based on findings, we recommend to use the alternative renewable sources of energy consumption to avoid the pollution effects of growth in Saudi Arabia.

\section{Introduction}

The energy sector is multi-dimensional and does not operate in a parallel segment to the actual economic domain. There are countless activities in the energy sector that have the ability to impact the rest of the country and vice versa. Whenever an economic activity takes place in a country, the energy sector is inclined to receive some of the most intense results which can impact the domain in a positive or a negative way. It is mentioned by Mahmood et al. (2019c) that there seems to be a relationship between the energy sector and trade openness. The country they selected for the analysis was Tunisia and data from 1971-2014 was analysed to get to the results. Additionally, heavy pollution was found to exist in the country and the results indicated that higher foreign trade could lead to negative environmental effects in the country which is encouraging the initiatives to keep a balance between trade and ecological sustainability. According to Mahmood et al. (2019a), financial market development, trade openness and foreign direct investment have strong effects on $\mathrm{CO}_{2}$ emissions per capita. After analyzing data over the period 1991-2014 from East Asian countries, spillover effects of these variables were also proven which indicated that foreign trade activities of a country not only impact its own environment but the environment of the neighboring nations as well. Environmental Kuznets Curve (EKC) was proven to be hold in the region but trade activities and financial market development seemed to impact the environmental profile of the country, leading to a degradation in its ecological footprint. The results suggest a strong implication for countries in the Asian region and suggest that these countries should not only think about their own economies but also they need to keep the economic and environmental profile of the

* Corresponding author.

E-mail address: haidermahmood@hotmail.com (H. Mahmood) 
neighboring countries into consideration which can be a huge challenge. All in all, economic activities and outcomes can lead to changes in the environmental domain as well which can put countries in a challenging situation where they have to make some tough decisions. In the context of Pakistan, a study conducted an analysis on an annual dataset from 1977 to 2013 . Longrun relationship and Granger causality were checked for energy-led growth variables and energy conservation strategies. It was mentioned that energy conservation strategies can harm economic growth of the country while gas-usage can have a significantly positive effect in income of the country (Hassan et al., 2017). The study provided strong policy implications for the Pakistan economy. However, context was not provided in detail which left some space for further research. That is something similar this current study is focused on analyzing the context of Saudi Arabia.

In their research, Mahalik et al. (2017) mentioned that Financial Development (FD) could lead to a higher level of Energy Consumption (EC) and they conducted this analysis on the Kindom of Saudi Arabia. As a reasonable implications to this analysis, economic growth can lead to a higher level of energy consumption, which in turn, can lead to higher $\mathrm{CO}_{2}$ emissions. One way or another, it can be said that a higher level of economic activity can make the environment worse because it leads to a higher level of energy consumption in the state. In this context, the idea of EKC should also be kept into account according to which, economic growth can lead to $\mathrm{CO}_{2}$ emissions but with time, those emissions start to reduce once the country becomes technologically advances. In the Saudi Arabia economy, the existence of EKC was proven in the analysis but further analysis is required to isolate whether $\mathrm{CO}_{2}$ emissions get affected by income and energy consumption, which is something this current study aims to analyze. Talking about the Saudi economy, it is a huge economy and that is one of the major reasons the context of oil prices and other related activities cannot be ignored. Incorporating oil prices in the analysis can provide more context to a certain level while the environmental profile of the country gets formed. Mahmood and Zamil (2019) argued that energy consumption seem to have a long-term relationship in the country from 1970 to 2016. The results suggest that oil prices impact the energy consumption in the country to a significant extent which indicates that the energy sector is directly tied to activities in the macroeconomic context. A similar analysis was provided in the study by Mahmood and Alkhateeb (2017) who mentioned that trade activities and the environment are closely linked in the country and share a long-term relationship. Trade seemed to have a negative effect on the country which indicates that trade could help keep the environment in a good shape. It was suggested that the Saudi government liberalizes the economy so that more trade activities can lead to a better environment (Mahmood et al., 2019b).

Our hypothesized study can help complement other studies conducted on a similar topic in Saudi Arabia. The output generated through the study will help suggest and devise strong policy for the energy sector of the country so that a balance between the economic and the energy segments can be maintained and nothing slips through the cracks which come back and gives a destructive hit to the Saudi economy. Additionally, a long-term macroeconomic policy can be designed around the answers and other research so that sustainable growth in the Kingdom is ensured.

\section{Literature Review}

There is a bunch of literature on the idea of $\mathrm{CO}_{2}$ emissions and how this gets affected by other macroeconomic variables. Sadorsky (2011) conducted a study on the idea in the Middle Eastern region and analysed how these two major variables can be associated with each other. Data collected for the study was from 1980-2007 and a long-term panel data was investigated. In the selected 8 Middle-Eastern countries, causality was seen. It means that when these countries export more products to other nations, energy consumption increases and on the other hand, higher energy consumption can help increase the trade relations that these nations have with others. On a long-term basis, these results can have a strong implication for any country and nations need to address the matter of energy consumption as well while devising their trade policy. The results also indicate that the macroeconomic segment and trade segments are directly and significantly related to each other. Another study that supports a similar idea in the context of Egypt was conducted by Alkhateeb and Mahmood (2019) who mentioned that while trade can lead to economic growth in a country, it does intensify the consumption level of energy, which in turn can increase the $\mathrm{CO}_{2}$ emissions that a country produces. An increase in the income or improvement in the economic growth levels of a country can increase energy consumption as well which can have an environmental degradation impact on the country in general. The results suggested that countries should consider the effects of their macroeconomic and international trade policies on the environmental side and explore the way it can impact the ecological footprint of the country in the neighbourhood. Mahmood et al. (2018) analyzed the pollution in Saudi Arabia. Data from 1971-2014 was analyzed from the Saudi Arabia and both short and long-term relationships were analyzed. The results of the study provided evidence for the EKC which suggested that as the Saudi economy starts achieving higher income levels, pollution in the country starts to increase. However with time, these higher economic growth levels can help reduce these $\mathrm{CO}_{2}$ emissions eventually and help the economy. One thing to keep into account is the role that FD and international trade play in this equation. With a higher rate of energy consumption, $\mathrm{CO}_{2}$ emissions seem to increase both in a short and a long-term basis. The idea makes theoretical and practical sense as well because with more energy consumption, more fuel will be burned and resources will be consumed at a faster rate which will eventually increase emissions generated by these sources. Additionally, income and pollution also seem to share a significant relationship and with higher income, $\mathrm{CO}_{2}$ emissions tend to increase due to the higher use of energy consumption per capita.

One interesting aspect analysed in the literature is what type of energy consumption can lead to higher $\mathrm{CO}_{2}$ emissions rate and what role economic growth plays in that discussion. It must be noted that energy from all sorts of sources does not 
necessarily impact the economy and $\mathrm{CO}_{2}$ emissions in the same and these effects can vary on a wide scale. On top of that, what type of energy is being used and what source was used to generate that energy can impact the final outcome as well. For instance, renewable energy consumption might destruct the environment as much as any non-renewable energy can. In some instances, it is even possible that the increasing EC can lead to economic growth and does not affect the $\mathrm{CO}_{2}$ emissions at all but all of that depends on the source of energy being consumed by the users. Renewable energy can drive income and the effect is not the same for other energies. Additionally, the industrial sector can have more intense effects on the environment since the volume of this energy is much larger than the domestic one (Narayan \& Doytch, 2017; Ahmad et al., 2013).

Valadkhani et al. (2019) analysed the effects that EC has on the pollution levels in a country. The sample for the analysis consisted of 60 countries and data was collected from 1965 to 2016 . The research piece made a similar argument that the sources of energy can have varying impacts on the $\mathrm{CO}_{2}$ emissions level and that is why each of them has to be analysed for its unique effects. Oil, coal, gas, hydroelectric and other renewables were analysed in the paper and the level of $\mathrm{CO}_{2} \mathrm{emissions}$ they generated was observed. It was mentioned that the $\mathrm{CO}_{2}$ emission resulted from energy consumption based on their sources could get affected by the real income level of the nation. With over 2600 observations from 60 countries, data was collected and findings suggested that countries face a trade-off between switching to different fuels and maintaining an income level while they target a certain economic growth level. There is a strong policy implication of how fuel consumption can generate more energy used in various segments of the country and as a result, $\mathrm{CO}_{2}$ emission levels can vary to a wide extent. This raises a question for economies to determine energy demand in their countries to ensure that there is a balance on both sides of the equation and one does not destruct the other. In that discussion, Alarenan et al. (2019) contributed by analysing the EC in Saudi Arabia and exploring how it affects economic efficiency and other macroeconomic variables in the country. Through their significantly strong relationship, income and EC can be used in a predictability model to explore the directions where both variables were prone to take in the near future. These levels, in turn, can help diagnose the levels of $\mathrm{CO}_{2} \mathrm{emissions} \mathrm{that}$ are expected to be generated in a country or a region. With an energy consumption, income per capita of the nation can be predicted and these results can be used for future policy making processes. For a long-term, a country can benefit from this relationship since it can help construct a model for the economic and environmental policy at the same time (Narayan, 2016).

According to Alkhathlan and Javid (2013), EC, pollution and income are strongly connected in the Saudi economy and these are one of the major reasons the environment should be kept into account while devising a policy for the country. It was seen that $\mathrm{CO}_{2}$ emissions can increase as the country achieves a higher level of income which indicates that energy consumption activities are driven by higher income patterns in the Kingdom. On the other hand, the study segregated the analysis for various types of energy including gas and oil. It was concluded that gas consumption had negative income elasticity while the instrument for oil consumption was positive, suggesting a completely opposite relationship. The results suggested that the country needs to make decisions in terms of which type of energy should be used to produce electricity as it can change the energy consumption patterns in the nation and get influenced by income as well. The relationship of these variables was seen to be strong in the long-run than a short-run but a monotonically increasing relationship is suggesting that emissions keep increasing as a result of a higher income. A similar study was conducted by Akadiri et al. (2019) and in their analysis, they talked about the role that EC plays in the Saudi economy and it affects the environmental quality. The role of international trade was also discussed in the study and data from 1968 to 2016 was collected to conduct a time series analysis. With the help of a cointegration, it was suggested that these variables had a positive relationship which indicates that higher trade activity and national income could lead to higher energy consumption, specifically gas. So, a higher natural gas consumption, $\mathrm{CO}_{2}$ emissions of country influence on the environment and proves to be degrading in the long-term. The findings suggest the Saudi government should keep a balance between energy consumption and its environmental profile so that it would not become degrading for the ecosystem.

Energy consumption can be influenced by financial developed as well which can turn into a higher rate of pollution while these two variables share an inverted U-shaped relationship (Gaies et al., 2019). These three variables of EC, pollution and income seem to share a strong relationship that has to do with their macroeconomic dynamics as well. With more income, EC in the region starts to increase which comes at the cost of a higher rate of $\mathrm{CO}_{2}$ emissions. Focusing on income and $\mathrm{EC}$ which can make the environment worse because of the higher and higher rate of emissions. On the other hand, if a country focuses on implementing an energy conservation policy, it does not necessarily mean that the income of that country will start to decline. Countries can still focus on reducing their energy consumption without having to let it impact their national income and economic growth (Gorus \& Ayedin, 2019). A similar analysis was conducted by Muhammad (2019) who suggested that energy consumption tends to increase with more economic activities in the panel of 68 countries. While higher energy consumption leads to higher $\mathrm{CO} 2$ emissions, the results might not necessarily increase the national income. In emerging countries, $\mathrm{CO}_{2}$ emissions can decrease as a result of economic growth in those nation which is an interesting dynamic to explore in the literature and provides a strong base for further foundation on the idea that the type of economy matters a lot in terms of what sort of effect various macroeconomic and environmental policies have on a country. For a country like Saudi Arabia, smarter electricity grids might be a better solution to save energy and ensure that the impact these policies have on the environment goes in the right direction (Dustegor et al., 2018). Ahmed and Azam (2016) talked about a similar relationship and mentioned that countries might react to these policies differently but there is certainly a relationship between $\mathrm{EC}, \mathrm{CO}_{2}$ emissions and income in most part of the world which requires extensive policy making to be kept under control. Mezghani and Haddad (2017) talked about EC and income and the association of these variables share in Saudi Arabia. Using data from 1971 to 2010 , it was argued that the relationship of these variables can depend on the volatility of the real income of the country and 
if there is a high level of volatility, it means that the country should consider extensive policy-making to ensure that $\mathrm{CO}_{2}$ emissions decline with time. This current study fills in on the literature pool and discusses how $\mathrm{CO}_{2}$ emissions are determined through EC and income level in Saudi Arabia.

\section{Research Methodology}

This study objects to find the role of basic determinants of $\mathrm{CO}_{2}$ emissions which are EC and Economic Growth (EG). With increasing income and in the process of EG, a significant amount of energy is required to fuel the economic activities. Particularly, energy is highly demanded in the production sector to run the machinery. Further, infrastructure and transportation activities increase with the economic growth. Both requires energy to work and direct air pollution is also expected. Lastly, the increase in personal consumption due to increasing economic growth is also responsible for increasing energy demand for household utensils and the personal vehicles. The increasing energy consumption might be responsible for higher $\mathrm{CO}_{2}$ emissions as a major part of EC is from the fossil fuel sources in the Kingdom. To capture the effects of such determinants, we hypothesize the following model:

$$
C O_{t}=f\left(E G_{t}, E C_{t}\right)
$$

Here, $\mathrm{CO}_{\mathrm{t}}$ is $\mathrm{CO}_{2}$ emissions to quantify the pollution. $\mathrm{EG}_{\mathrm{t}}$ represents the economic growth which captures the economic activities which are responsible for higher energy consumption and resultant pollution. $\mathrm{EC}_{\mathrm{t}}$ is energy consumption as most of it consisted of fossil fuels in the Saudi Arabia. Therefore, it is a major reason for pollution emissions in the Kingdom. We convert all variables in natural logarithm to have elasticity parameters from coefficients. Data on all variables is collected from World Development Indicators of period 1968-2014. Before starting the regression analysis, we will first test unit root in Eq. (1) and will proceed further once ensure the stationarity of the all series. To serve the purpose, we will utilize the Dickey Fuller-Generalized Least Square (DF-GLS). After ensuring the order of integration in the Eq. (1), we follow the cointegration. For cointegration, we are using the Auto-Regressive Distributive Lag (ARDL) model of Pesaran et al. (2001) on the equation 1 in following way:

$$
\begin{aligned}
& \Delta C O_{t}=\delta_{0}+\delta_{1} C O_{t-1}+\delta_{2} E G_{t-1}+\delta_{3} E C_{t-1} \\
& +\sum_{j=1}^{p} \phi_{1 j} \Delta C O_{t-j}+\sum_{j=0}^{q} \phi_{2 j} \Delta E G_{t-j}+\sum_{j=0}^{r} \phi_{3 j} \Delta E C_{t-j}+\psi_{i t} .
\end{aligned}
$$

Equation could be verified for an existence of cointegration with $\delta_{1}=\delta_{2}=\delta_{3}=0$ null hypothesis. Rejection of it may evidence the cointegration in the Eq. (2). Null-hypothesis will be tested after selection of optimum lag length $p, q$ and $r$ in Eq. (2). Moreover, all diagnostic tests will also be performed on Eq. (2) to ensure the consistency and reliability of the estimated equation. Afterwards, we will normalize $\delta_{2}$ and $\delta_{3}$ by $\delta_{1}$ to capture the long run elasticity parameters in the effects of EG and $\mathrm{EC}_{\mathrm{t}}$ on the $\mathrm{CO}_{\mathrm{t}}$ from Eq. (2). After that, the short run effects may also be estimated from the following:

$$
\Delta C O_{t}=\delta_{0}+\sum_{j=1}^{p} \vartheta_{1 j} \Delta C O_{t-j}+\sum_{j=0}^{q} \vartheta_{2 j} \Delta E G_{t-j}+\sum_{j=0}^{r} \vartheta_{3 j} \Delta E C_{t-j}+v E C T_{t-1}+\psi_{i t}
$$

Eq. (3) will corroborate the existence of short run relationship if $v$ is found negative and significant. It will also represent the speed of convergence. Afterwards, estimated coefficients of differenced variables in Eq. (3) can be considered as short run elasticity parameters.

\section{Data Analyses}

In the estimation procedure, we start with unit root testing through DF-GLS and outcome are shown in Table 1. The results expose that all variables are non-stationary at levels but are stationary after differencing. Therefore, order of integration is one which is fine for cointegration analysis. So, we proceed for ARDL cointegration analysis.

\section{Table 1}

DF-GLS Unit Root Test Results

\begin{tabular}{lll}
\hline Variable & Intercept & Intercept and Trend \\
\hline $\mathrm{CO}_{\mathrm{t}}$ & $-0.7561(0)$ & $-2.2157(0)$ \\
$\mathrm{EG}_{\mathrm{t}}$ & $-1.6201(1)$ & $-2.0667(1)$ \\
$\mathrm{EC}_{\mathrm{t}}$ & $0.0562(0)$ & $-1.2541(0)$ \\
$\Delta \mathrm{CO}_{\mathrm{t}}$ & $-5.6149(0) * * *$ & $-6.6022(0) * * *$ \\
$\Delta \mathrm{EG}_{\mathrm{t}}$ & $-3.6580(1) * * *$ & $-3.5918(1) * * *$ \\
$\Delta \mathrm{EC}_{\mathrm{t}}$ & $-2.9940(1) * * *$ & $-3.9707(0) * * *$ \\
\hline
\end{tabular}

$* * *$ shows are stationary at $1 \%$ level of significance.

The estimated long- and short-run elasticities parameters from selected ARDL model of equations 2 and 3 are reported in the Table 2. At first, we apply the bound test on the hypothesis $\delta_{1}=\delta_{2}=\delta_{3}=0$ to verify the long run relationships in Eq. (2). The estimated F-value of bound test is high enough to reject the $\delta_{1}=\delta_{2}=\delta_{3}=0$ and we may claim the cointegration in Eq. (2). 
Further, diagnostic tests are applied and we find the lower F-values and higher p-values which corroborated that our model has no econometric problem to proceed.

Table 2

ARDL Cointegration Results

\begin{tabular}{llll}
\hline Variable & Coefficient & Std. Error & t-Statistic \\
\hline Long Run & & & \\
$\mathrm{EG}_{\mathrm{t}}$ & 0.5716 & 0.2608 & 2.1913 \\
$\mathrm{EC}_{\mathrm{t}}$ & 0.4226 & 0.1212 & 3.4873 \\
Intercept & -7.2426 & 3.7854 & -1.9133 \\
Short Run & & & 0.0352 \\
$\Delta \mathrm{EG}_{\mathrm{t}}$ & 0.7351 & 0.1838 & 0.0013 \\
$\Delta \mathrm{EC}_{\mathrm{t}}$ & 0.5161 & 0.1795 & 3.9996 \\
$\Delta \mathrm{EC}_{\mathrm{t}-1}$ & -0.3333 & 0.1733 & 2.8753 \\
$\mathrm{ECT}_{\mathrm{t}-1}$ & -0.4321 & 0.1264 & -1.9237 \\
\hline Diagnostic Tests & & & -3.4195 \\
Bound Test $_{\text {Heteroscedasticity }}$ & F-value $=4.0968$ & & 0.0003 \\
Serial Correlation & F-value $=0.4362$ & & 0.0668 \\
Functional Form & F-value $=0.6099$ & & 0.0016 \\
\hline & & & 0.8496 \\
\end{tabular}

The long results depict in Table 2 that $\mathrm{EG}_{\mathrm{t}}$ has positive and significant parameters. It shows that $\mathrm{EG}_{\mathrm{t}}$ has positive effects on $\mathrm{CO}_{2}$ emissions. Elasticity parameter shows that $1 \%$ increasing $\mathrm{EG}_{\mathrm{t}}$ may increase $0.5716 \%$ of the $\mathrm{CO}_{2}$ emissions in the kingdom. It corroborates that increasing economic growth is responsible for increasing domestic and commercial energy consumption which resultantly pollute the environment by emitting the $\mathrm{CO}_{2}$ emissions. The direct effect of $\mathrm{EC}_{\mathrm{t}}$ is also found positive and significant. It means that energy consumption is contributing in the $\mathrm{CO}_{2}$ emissions of the Kingdom. It may also be verified from a fact that most of energy consumption of the Saudi Arabia is from the fossil fuel sources so increasing fossil fuel energy consumption is contributing the $\mathrm{CO}_{2}$ emissions. Its elasticity parameter suggests that $1 \%$ increasing $\mathrm{EC}_{\mathrm{t}}$ may increase $0.4226 \%$ of the $\mathrm{CO}_{2}$ emissions. Table 2 also represents the short run results. Negative coefficient of ECT $\mathrm{t}_{\mathrm{t}-1}$ shows the existence of short-run association and convergence speed is at $0.4321 \%$ in a year after any disequilibrium towards the equilibrium. Further, $\mathrm{EG}_{\mathrm{t}}$ has positive influence on $\mathrm{CO}_{2}$ emissions. Moreover, $1 \%$ increase in $\mathrm{EG}_{\mathrm{t}}$ in short run may increase $0.7351 \%$ of the $\mathrm{CO}_{2}$ emissions. The effect of $\mathrm{EC}_{\mathrm{t}}$ on $\mathrm{CO}_{2}$ emissions is also found positive. Moreover, the elasticity parameter suggests that $1 \%$ increasing $\mathrm{EC}_{\mathrm{t}}$ may increase the $0.5161 \%$ of the $\mathrm{CO}_{2}$ emissions. In last, the lag of $\mathrm{EC}_{\mathrm{t}}$ shows a negative effect.

\section{Conclusions}

Economic growth is very desirable phenomena in any economy but its negative spillovers in terms of pollution are also existing. We have investigated the effects of EG and EC on the $\mathrm{CO}_{2}$ emissions in the Kingdom using a period 1968-2014 and the ARDL cointegration test. We have corroborated the existence of long- and short-run relationships in the $\mathrm{CO}_{2}$ emissions model. Moreover, we have discovered that EG is accountable for higher $\mathrm{CO}_{2}$ emissions. It means that increasing economic growth is increasing the demand for pollution-oriented consumption. It is also due to a reason that increasing economic growth is boosting the economic activities and developmental activities as well which require energy consumption to run. The increasing energy consumption is also responsible for higher $\mathrm{CO}_{2}$ emissions. It is also corroborated by the estimated direct effect of EC. It highlights the fact that most of energy consumption is from fossil-fuel in the Kingdom and not from renewable energy sources. Therefore, increasing economic activities and energy consumption are contributing to the $\mathrm{CO}_{2} \mathrm{emissions} \mathrm{We}$ recommend the Saudi economy to use the other renewable energy consumption sources to avoid the negative environmental effects of EG and EC in the Kingdom.

\section{Acknowledgement}

This project was supported by Deanship of Scientific Research at Prince Sattam bin Abdulaziz University Alkharj under the project NO. 2019/02/10499.

\section{References}

Ahmad, N., Iqbal, A. \& Mahmood, H. (2013). $\mathrm{CO}_{2}$ Emission, population and industrial growth linkages in selected South Asian countries: A co-integration analysis. World Applied Sciences Journal, 21(4), 615-622.

Ahmed, M., \& Azam, M. (2016). Causal nexus between energy consumption and economic growth for high, middle and lowincome countries using frequency domain analysis. Renewable and Sustainable Energy Reviews, 60, 653-678.

Akadiri, A., Akadiri, S., \& Gungor, H. (2019). The role of natural gas consumption in Saudi Arabia's output and its implication for trade and environmental quality. Energy Policy, 129, 230-238.

Alarenan, S., Gasim, A., \& Hunt, L. (2019). Modelling industrial energy demand in Saudi Arabia. Energy Economics, 1-20.

Alkhateeb, T., \& Mahmood, H. (2019). Energy consumption and trade openness nexus in Egypt: Asymmetry Analysis. Energies, 12(10), 2018. 
Alkhathlan, K., \& Javid, M. (2013). Energy consumption, carbon emissions and economic growth in Saudi Arabia: An aggregate and disaggregate analysis. Energy Policy, 62, 1525-1532.

Dustegor, D., Sultana, N., Felemban, N., \& Qahtani, D. (2018). A smarter electricity grid for the eastern province of Saudi Arabia: Perceptions and policy implications. Utilities Policy, 50, 26-39.

Gaies, B., Kaabia, O., Ayadi, R., Guesmi, K., \& Abid, I. (2019). Financial development and energy consumption: Is the MENA region different? Energy Policy, 135.

Gorus, M., \& Ayedin, M. (2019). The relationship between energy consumption, economic growth and CO2 emissions in the MENA countries: Causality analysis in the frequency domain. Energy, 168, 815-822.

Hassan, M., Tahir, M., Wajid, A., Mahmood, H., \& Farooq, A. (2017). Natural gas consumption and economic growth in Pakistan: Production function approach. Global Business Review, 19(2), 1-14.

Mahalik, M., Babu, S., Loganathan, N., \& Shahbaz, M. (2017). Does financial development intensify energy consumption in Saudi Arabia? Renewable and Sustainable Energy Reviews, 75, 1022-1034.

Mahmood, H., \& Alkhateeb, T. (2017). Trade and environment nexus in Saudi Arabia: An environmental kuznets curve hypothesis. International Journal of Energy Economics and Policy, 7(5), 291-295.

Mahmood, H., \& Zamil, A. (2019). Oil price and slumps effects on personal consumption in Saudi Arabia. International Journal of Energy Economics and Policy, 9(4), 1-4.

Mahmood, H., Alrasheed, A., \& Furqan, M. (2018). Financial market development and pollution nexus in Saudi Arabia: Asymmetrical Analysis. Energies, 11(12), 3462.

Mahmood, H., Furqan, M., \& Bagais, O. (2019a). Environmental accounting of financial development and foreign investment: Spatial analyses of east Asia. Sustainability, 11(1), 0013.

Mahmood, H., Furqan, M., Alkhateeb, T., \& Fawaz, M. (2019b). Testing the environmental Kuznets curve in Egypt: Role of testing the environmental Kuznets curve in Egypt: Role of. International Journal of Energy Economics and Policy, 9(2), 225-228.

Mahmood, H., Maalel, N., \& Zarrad, O. (2019c). Trade openness and CO2 emissions: Evidence from Tunisia. Sustainability, 11(12), 3295.

Mezghani, I., \& Haddad, H. (2017). Energy consumption and economic growth: An empirical study of the electricity consumption in Saudi Arabia. Renewable and Sustainable Energy Reviews, 75, 145-156.

Muhammad, B. (2019). Energy consumption, CO2 emissions and economic growth in developed, emerging and middle east and North Africa countries. Energy, 179, 232-245.

Narayan, S. (2016). Predictability within the energy consumption-economic growth nexus: Some evidence from income and regional groups. Economic Modelling, 54, 515-521.

Narayan, S., \& Doytch, N. (2017). An investigation of renewable and non-renewable energy consumption and economic growth nexus using industrial and residential energy consumption. Energy Economics, 68, 160-176.

Pesaran, M.H., Shin, Y., Smith, R.J. (2001), Structural analysis of vector error correction models with exogenous I(1) variables. Journal of Econometrics, 97(2), 293-343.

Sadorsky, P. (2011). Trade and energy consumption in the Middle East. Energy Economics, 33, 739-749.

Valadkhani, A., Smyth, R., \& Nguyen, J. (2019). Effects of primary energy consumption on CO2 emissions under optimal thresholds: Evidence from sixty countries over the last half century. Energy Consumption, 80, 680-690.

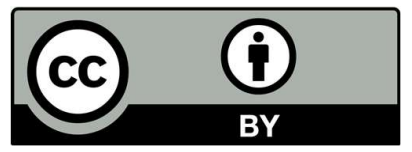

(C) 2019 by the authors; licensee Growing Science, Canada. This is an open access article distributed under the terms and conditions of the Creative Commons Attribution (CCBY) license (http://creativecommons.org/licenses/by/4.0/). 